NBER WORKING PAPER SERIES

\title{
COMPETITION AMONG HOSPITALS
}

\author{
Martin Gaynor \\ William B. Vogt \\ Working Paper 9471 \\ http://www.nber.org/papers/w9471
}
NATIONAL BUREAU OF ECONOMIC RESEARCH
1050 Massachusetts Avenue
Cambridge, MA 02138
January 2003

Thanks are due to Dan Ackerberg, Ted Frech, Gautam Gowrisankaran, Phillip Leslie, Aviv Nevo, Tom Philipson, Bob Pollack, Catherine Wolfram, and participants in seminars at BYU, Minnesota, NBER, Penn, UCLA, UC Santa Barbara, Washington University, the $10^{\text {th }}$ Annual Health Economics Symposium at UC Berkeley, and the 1999 Stanford Institute for Theoretical Economics Summer Workshop for useful comments. The usual caveat applies. The views expressed herein are those of the authors and not necessarily those of the National Bureau of Economic Research.

(C)2003 by Martin Gaynor and William B. Vogt. All rights reserved. Short sections of text not to exceed two paragraphs, may be quoted without explicit permission provided that full credit including notice, is given to the source. 
Competition Among Hospitals

Martin Gaynor and William B. Vogt

NBER Working Paper No. 9471

January 2003

JEL No. L1, L4, I1

\section{$\underline{\text { ABSTRACT }}$}

Our objective is to determine the effect of ownership type (for-profit, not-for-profit, government) on firm conduct in hospital markets. Secondary objectives include estimating hospital demand systems useful for market definition and merger simulation. To this end, we estimate a structural model of demand and pricing in the short term hospital industry in California, and then use the estimates to simulate the effect of a merger. Demand is modeled at the level of individual consumers using discrete choice techniques and micro data on individuals. Price in the demand equation is endogenous, and we use recently developed instrumental variables techniques to correct for this. We allow the behavior of for-profit and not-for-profit firms to differ, modeling these differences structurally following the relevant theory literature. We find that California hospitals in 1995 faced a downward-sloping demand for their products, with an average price elasticity of demand of -5.67. Not-for-profit hospitals face less elastic demand and have lower marginal costs. Their prices are lower, but markups are higher than those of for-profits. We simulate the effects of the 1997 merger of two hospital chains. In unconcentrated markets such as Los Angeles and San Diego, the merger has virtually no effect on prices. However, in San Luis Obispo County, where the merger creates a near monopoly, prices rise by up to $58 \%$, and the predicted price increase would not be substantially smaller were the chains to be not-for-profit.

Martin Gaynor

H. John Heinz III School

of Public Policy and Management

Carnegie Mellon University

Pittsburgh, PA 15213-3890

and NBER

mgaynor@andrew.cmu.edu
William B. Vogt

H. John Heinz III School of Public Policy and Management

Carnegie Mellon University

Pittsburgh, PA 15213-3890

and NBER

wilibear@andrew.cmu.edu 


\section{Introduction}

One of the most important industries in the United States economy is health care, accounting for over one trillion dollars in expenditure annually. This industry is also one in which competition is a real issue, given the extensive consolidation that has occurred in recent years (Gaynor and Haas-Wilson, 1999).

During the second half of the 1990s, a dramatic wave of hospital consolidation occurred in the United States. One source puts the total number of hospital mergers from 1994-2000 at over 900 deals (Jaklevic, 2002, and www.levinassociates.com), on a base of approximately 6,100 hospitals. Further, many local markets including quite a few large cities such as Boston, Minneapolis, and San Francisco, have come to be dominated by 2-3 large hospital systems. Not surprisingly, many health plans have complained about rising prices as a result of these consolidations (Lesser and Ginsburg, 2001).

This transformation raises concerns about impacts on competition, and emphasizes the need for a better understanding of the nature of competition in these markets. Of particular interest is the difference in behavior between for-profit (FP hereafter) and not-for-profit (NFP hereafter) hospitals.

Hospital markets have been an active area of antitrust enforcement. Since 1984, the federal antitrust authorities have brought 11 suits seeking to block hospital mergers, but have not won a case (of 6) since 1991. ${ }^{1}$ NFP status has played a key role in hospital antitrust cases. NFP hospitals wishing to merge have argued that they will not raise prices after merging since they are motivated by community interest rather than private profit. Courts'

\footnotetext{
${ }^{1}$ The Federal Trade Commission (FTC) won one case, but was subsequently reversed on appeal.
} 
reactions to this have ranged from sympathetic - "The board of University Hospital is quite simply above collusion" ${ }^{2}$ to outright rejection - "no one has shown that [NFP status] makes the enterprise unwilling to cooperate in reducing competition . . . which most enterprises dislike and which nonprofit enterprises may dislike on ideological as well as selfish grounds." 3 On balance, however, the courts have been receptive to this line of argument, particularly in recent years, and the only recent case in which the government has prevailed involved two FP hospitals ${ }^{4}$ (see Gaynor and Vogt, 1999).

Hospitals sell products that are differentiated on a number of dimensions. One of the most important dimensions is physical location. Hospitals have their physical plant in distinct locations, and consumers value proximity to their residences. ${ }^{5}$ Hospitals also have different religious affiliations. They are differentiated in the breadth of product line they offer, in the technological sophistication of their services, in the quality of the "hotel" services they offer, in their use and deployment of staffing, in their mortality rates, and probably in other dimensions as well. It seems reasonable, therefore, to model hospital competition using models of differentiated oligopoly (see, for example, Hausman and Leonard, 1997; Werden, 1997; Anderson et al., 1992; Baker and Breshahan, 1985).

One of the most important research areas in modern industrial organization is differentiated product oligopoly. A great deal of effort has been devoted in recent years to developing

\footnotetext{
${ }^{2}$ From the District Court's decision in the Augusta, GA hospital merger case, FTC v. University Health, 1991-1 Trade Cases $\uparrow 69,444$.

${ }^{3}$ Judge Posner in HCA vs. FTC (1986, 807 F2d 1381).

${ }^{4}$ The "Poplar Bluff" case, FTC v. Tenet Healthcare (1998, US Dist Lexis 11849). Even in this case, however, the government subsequently lost on appeal.

${ }^{5}$ This is also true of many other industries. A number of recent papers in industrial organization have focused specifically on the spatial dimension of product differentiation (e.g., Davis, 2000; Manuszak, 1999; Seim, 2001; Pinkse et al., 2002; Thomadsen, 2002).
} 
econometric models to investigate the workings of such markets. Berry, Levinsohn, and Pakes, in particular, have developed econometric models for estimating models of differentiated product oligopoly (Berry, 1994; Berry et al., 1995, 1998). These models have been applied to a variety of industries: automobiles (Berry et al., 1995), (Berry et al., 1998), ready-to-eat breakfast cereal (Nevo, 2000); retail gasoline (Manuszak, 1999); and movies (Davis, 2000). We contribute to this literature by examining the market for hospital services. By virtue of the data collected for this industry we can use micro data on individuals, which to our knowledge has not been utilized in other econometric studies of differentiated product oligopoly, with the exception of (Berry et al., 1998). The availability of detailed micro data allow us to flexibly model individual heterogeneity with a directness not possible with aggregate data, since important sources of individual heterogeneity are observable in the data.

An added complexity in the case of hospitals is that many hospitals are NFP organizations. ${ }^{6}$ A literature has grown up around the idea that NFP hospitals, unlike other firms, do not maximize profits, but rather some utility function, possibly reflecting the preferences of the board of trustees, the administrators, the employees more generally, or the physician staff (Newhouse, 1970; Pauly and Redisch, 1973; Lee, 1971; Lakdawalla and Philipson, 1998), and our model reflects the potential for preference differences in the different forms.

To date, the hospital competition literature has consisted largely of structure-conductperformance (SCP) studies. These studies have found that, at least during the 1990s, hospital prices are lower in less concentrated markets. There are several reviews of this literature

\footnotetext{
${ }^{6} 60 \%$ of hospitals and $70 \%$ of hospital beds were NFP in 1995 (AHA, 1997).
} 
available (Gaynor and Vogt, 2000; Dranove and Satterthwaite, 2000; Dranove and White, 1994), so we will not offer a further review here. There is more variation in the results of the small number of studies which examine this relationship for NFPs and FPs separately, however. Three of these papers find that both NFP and FP hospitals set higher prices in more concentrated markets(Dranove and Ludwick, 1999; Keeler et al., 1999; Simpson and Shin, 1997). Two others, however, find that NFP hospitals set lower prices in more concentrated markets, while FPs set higher prices(Lynk, 1995; Lynk and Neumann, 1999). While the results from this literature are interesting, SCP methods suffer from well known deficiencies for testing hypotheses about competitive conduct. In addition, this type of modeling makes it extremely difficult to sort out the differences in results between the studies of NFP pricing. These studies cover different time periods, use different geographic and product markets, and employ different functional forms. The reduced form framework makes it difficult to assess the reasons for the different results across these studies, let alone evaluate their relative merits.

There is also an emerging structural hospital competition literature. In this literature, consumer-level data are used to estimate models of demand for hospital services, and then the information from the demand estimation is used to calculate the market power of various hospitals. Town and Vistnes (2001) and Capps et al. (2001b) each use their demand systems to calculate measures of the marginal value of adding each hospital to a network. Town and Vistnes (2001) then regress prices paid by health plans to hospitals on their measure of a hospital's marginal value and find that hospitals having a high marginal value, either because of isolation in product space or because of high average utility, receive higher payments. Capps 
et al. (2001b) regress their marginal value measure on hospital profit margins and similarly find a positive relationship. Capps et al. (2001a), in an approach similar to ours, use their demand estimates to simulate mergers and find that mergers of hospitals even in markets which look quite "competitive" by conventional antitrust methods would nevertheless lead to large price increases. Our work is differentiated from this literature primarily by our focus on the effects of not-for-profit status on pricing.

In this paper we estimate a structural model of hospital conduct, treating hospitals as operating in a differentiated product oligopoly and explicitly developing a model of hospital NFP vs. FP behavior. As part of this exercise, we estimate the demand for hospital services. We also estimate a pricing equation, and recover marginal cost parameters. Last, we use these estimates to simulate the effects of a merger. We simulate the effect of a merger between two hospital systems in California that occurred shortly after the time period our data cover. There was a federal antitrust intervention, so we can simulate the effect of the merger with and without the intervention.

We find that California hospitals in 1995 faced a downward-sloping demand for their products, with an average price elasticity of demand of -5.67. Not-for-profit hospitals face less elastic demand and have lower marginal costs. Their prices are lower, but markups are higher than those of for-profits. We simulate the effects of an actual merger and find no difference in the tendencies of not-for-profits versus for-profits to exploit merger-created market power. The simulation shows post-merger price increases of up to $58 \%$, regardless of whether the hospitals are for-profit or not-for-profit.

The paper is organized as follows. Section 2 contains a description of the model. Section 
3 describes the econometric specification. The data are discussed in Section 4. Section 5 contains our Results. In section 6, we report a merger simulation highlighting the FP/NFP distinction. A conclusion is contained in Section 7.

\section{Model}

We model hospital markets as a differentiated product oligopoly. Since our goal is a structural, estimable, model of demand and supply, we lay out the structure in terms of the demand and supply sides of the model. In what follows we first describe consumers, then producers. Since hospital care is heavily insured, and insurance companies often restrict consumers' choices, we take some care in specifying a model of consumer behavior that is consistent with the institutions in this market. On the supply side, we specify a model that takes the differing objectives of NFPs and FPs explicitly into account.

\subsection{Consumers - Basics}

Consumers have a utility function defined over consumption (of non-hospital goods) and the quantity and quality of inpatient hospital care consumed. This utility function depends upon both observable and unobservable (to the econometrician) consumer characteristics and upon both observable and unobservable hospital characteristics.

With some probability consumer $i(=1, \ldots, I)$ becomes ill. In this case, the utility he derives from consuming $q_{i}$ units of the inpatient good at hospital $j(=1, \ldots, J)$ is: 


$$
U_{i j}=u(C)+v\left(q_{i j}, R_{i}, S_{j}\right),
$$

where consumption of outside goods is C, the characteristics of hospital $j$ are $S_{j}$, and the characteristics of consumer $i$ are $R_{i}$. The functions $u$ and $v$ are assumed to be well-behaved utility functions.

\subsubsection{HMO Consumers}

Typically, however, consumers do not bear the cost of their hospitalization directly, as either all or most of the cost is borne by an insurer. Similarly, consumers' choices of both which hospital to patronize and what care to consume are determined substantially by their insurer through selective contracting and utilization review. ${ }^{7}$ This is especially true of HMO patients who often pay little or nothing when they consume care and whose utilization is often heavily managed by the HMO. ${ }^{8}$ Hence, we model the HMO's choices.

We posit a very simple model of HMO behavior. HMOs sell policies to consumers, consisting of a premium, $M$, and decision rules specifying the hospital to which a consumer will be sent and the quantity of care he will be provided, depending on his characteristics, $R_{i}$. We will denote the hospital-choice decision rule by a $J$-vector of indicator functions $\chi\left(R_{i}\right)$, where a 1 in the jth place indicates that a consumer with characteristics $R_{i}$ is sent to hospital $j$. We will write the jth function in this vector for the ith consumer in the mnemonically

\footnotetext{
${ }^{7}$ Consumers are also influenced by the advice of their doctors, who in turn are also often influenced by incentives from the insurer. We do not model the doctor-patient interaction here.

${ }^{8} \mathrm{HMOs}$ seek to limit medical expenditures by selectively contracting with health care providers, and most also attempt to control care via financial incentives for doctors.
} 
convenient notation, $\chi_{i \rightarrow j}$. The decision rule for quantity of care consumed is $q\left(R_{i}\right)$. We assume that $R_{i}$ is unobservable ex ante, so that the consumer evaluates the desirability of the HMO by its premium and its average quality, $\bar{v}=\int_{R_{i}} \sum_{j=1}^{J} \chi_{j}\left(R_{i}\right) v\left(q\left(R_{i}\right), R_{i}, S_{j}\right) d F_{R_{i}}$, i.e., the average utility across consumers from consuming hospital care.

Thus each HMO contract is characterized, for the consumers' purposes, by a pair, $(M, \bar{v})$. Different consumers choose different policies since their incomes differ. We are agnostic about the insurance market - by some means, $(M, \bar{v})$ are chosen for each insurer and consumers are allocated among them. ${ }^{9}$

The HMO must choose rules to assign consumers to hospitals, $\chi\left(R_{i}\right)$ and rules to assign quantities, $q\left(R_{i}\right)$. It does this to minimize costs subject to producing its chosen level of quality:

$$
\begin{aligned}
\min _{\chi(\bullet), q(\bullet)} \int_{R_{i}} \sum_{j} \chi_{j}\left(R_{i}\right) p_{j} q\left(R_{i}\right) d F_{R_{i}} \\
\text { s.t. } \int \sum_{j} v\left(q_{i}, R_{i}, S_{j}\right) d F_{R_{i}} \geq \bar{v} .
\end{aligned}
$$

Assuming that a solution exists, this problem is equivalent to solving the following problem for each consumer individually (where $\lambda$ is chosen such that the constraint is satisfied

\footnotetext{
${ }^{9} \mathrm{We}$ are assuming that the allocation is independent of consumer characteristics observable to the market participants but unobservable to the econometrician. We have not specified ex ante observable consumer characteristics in our model, however there certainly are such factors that affect $M$ and $\bar{v}$, e.g., age and sex. Therefore this analysis should be thought of as conditional on ex ante observables. When we discuss the solution below, it will also be conditional on ex ante observables. We are assuming, therefore, that HMOs can "price discriminate" among consumers with different observables and that they can offer them, either implicitly or explicitly, different decision rules in their benefits.
} 
at the solution): ${ }^{10}$

$$
\min _{\chi, q} \sum_{j} p_{j} q-\lambda v\left(q, R_{i}, S_{j}\right)
$$

Naturally, $\lambda$ will vary among health plans and on consumer ex ante observables, as different plans will choose to offer different levels of quality depending on local market conditions and the niche they wish to target.

We might just as well think of this problem as one of maximizing an "effective" utility function:

$$
\max _{\chi, q_{i j}}-\frac{1}{\lambda} p_{j} q_{i j}+v\left(q_{i j}, R_{i}, S_{j}\right)
$$

This problem is a discrete-continuous choice problem (Anderson et al., 1992; Dubin and McFadden, 1984). The solution can be thought of in two stages. After the choice of hospital, there is a choice of the optimal quantity:

$$
\max _{q_{i j}}-\frac{1}{\lambda} p_{j} q_{i j}+v\left(q_{i j}, R_{i}, S_{j}\right)
$$

Substituting the optimal quantity, $q_{i j}^{*}$ into the above yields an indirect effective utility

\footnotetext{
${ }^{10}$ For a proof, see the Appendix.
} 
function:

$$
V_{i j}^{*}\left(R_{i}, p_{j}, S_{j}\right)=-\frac{1}{\lambda} p_{j} q_{i j}^{*}+v\left(q_{i j}^{*}, R_{i}, S_{j}\right)
$$

The insurer then chooses the hospital with the greatest $V_{i j}$. So, the probability of a randomly selected consumer going to hospital $j$ is:

$$
P\{i \rightarrow j\}=\int_{V_{i j}^{*} \geq \max _{j}\left\{V_{i j}^{*}\right\}} d F_{R_{i}}
$$

This leads to total expected demand for hospital $j$ :

$$
D_{j}(p)=\int_{V_{i j}^{*} \geq \max _{j}\left\{V_{i j}^{*}\right\}} q_{i j}^{*} d F_{R_{i}} .
$$

We have characterized consumers with HMO insurance and the attendant demand facing hospitals from these consumers. We now turn to consumers with "traditional" insurance.

\subsubsection{Traditional Insurance Consumers}

We also model traditional insurance in a simple way. With traditional insurance (also referred to as "conventional," "fee-for-service," or "indemnity") consumers pay a premium and agree to pay a proportion of expenses (called "coinsurance"). The consumer is then free to choose 
where to obtain medical care when they fall ill.

A traditional insurance contract is thus a premium, $M$, and a coinsurance rate, $\tau$. The consumer chooses his own hospital and pays $\tau p_{j} q_{i j}$ for his care. The insurer then picks up the remaining $(1-\tau) p_{j} q_{i j}$.

In traditional insurance the consumer makes his treatment decisions to maximize utility over $\chi$ and $q$ :

$$
\max _{\chi, q} U_{i j}=u\left(I-M-\tau p_{j} q_{i j}\right)+v\left(q_{i j}, R_{i}, S_{j}\right)
$$

We assume that this utility is well-approximated by:

$$
U_{i j} \approx u(I-M)-u^{\prime}(I-M) \tau p_{j} q_{i j}+v\left(q_{i j}, R_{i}, S_{j}\right)
$$

Thus, we are effectively assuming either that marginal utility is constant in $C$ or that $\tau p_{j} q_{i j}$ is small relative to $I-M$. Either way, we still permit the marginal utility of income to vary among consumers. This assumption serves the purpose of leading the effective utility function to have the same structure as in the HMO case for our purposes (i.e. $u^{\prime}=1 / \lambda$ ) although from the perspective of the consumer, there is a difference. This then leads to a hospital's expected demand in the same way as in the previous section. 


\subsection{Production and Conduct}

Hospitals ("plants" or "brands") in our model produce a single output, inpatient hospital care, for which they charge a single price. ${ }^{11}$ A hospital $j$, with observable characteristics $Z_{j}$ and unobservable cost-shifters $\zeta_{j}$, charging a price $p_{j}$, facing other hospitals charging prices $p_{-j}$, and paying wages $W$ to its inputs, will earn profits of:

$$
\pi_{j}=p_{j} D_{j}(p)-C\left(D_{j}(p) ; Z_{j}, \zeta_{j}, W\right)
$$

A single-hospital, profit-maximizing firm playing a Bertrand pricing game sets its price according to the familiar first order condition:

$$
p_{j}=\frac{\partial C_{j}}{\partial D_{j}}-\frac{D_{j}}{\frac{\partial D_{j}}{\partial p_{j}}}
$$

Many hospital firms are NFP, and the theoretical literature typically deals with this by assuming that hospitals maximize a utility function, subject to a break-even constraint. A typical characterization is that NFP hospitals have a mission of providing care to the community. We capture this by specifying the utility function for NFPs as depending on quantity produced. We also include profits as an argument to capture any other objectives NFPs may have, thus $U_{N F P}=U(\pi, D)$. Hospitals then choose price to solve:

\footnotetext{
${ }^{11} \mathrm{~A}$ number of firms in this industry are multihospital systems, hence we treat individual hospitals as plants or brands.
} 


$$
\begin{aligned}
& \max _{p} U(\pi, D) \\
& \text { s.t. } \pi \geq \pi_{L}
\end{aligned}
$$

In the above, $\pi_{L}$, are the smallest profits (largest losses) a hospital may sustain. Below, $\mu$ is the Lagrange multiplier on this constraint. The problem leads to a pricing equation (again for a single-hospital firm playing a Bertrand game):

$$
p_{j}=\frac{\partial C_{j}}{\partial D_{j}}+\frac{\frac{\partial U_{j}}{\partial D_{j}}}{\frac{\partial U_{j}}{\partial \pi_{j}}+\mu_{j}}-\frac{D_{j}}{\frac{\partial D_{j}}{\partial p_{j}}}
$$

This equation suggests that the principal behavioral difference between FP and NFP firms is that NFP firms behave like FP firms with different cost functions (differing by the utility term - the second term in the expression above). This insight (due to Lakdawalla and Philipson, 1998) is formally correct in our setting with the additional assumptions that: 1) the marginal utility of profit is constant, and 2) the profit constraint does not bind. Under those conditions, NFPs behave exactly like FPs, except with different cost functions. Setting the marginal utility of profits to 1 (without further loss of generality), the previous equation reduces to: 


$$
p_{j}=\frac{\partial C_{j}}{\partial D_{j}}+\frac{\partial U_{j}}{\partial D_{j}}\left(D_{j}\right)-\frac{D_{j}}{\frac{\partial D_{j}}{\partial p_{j}}}
$$

This property has the benefit that standard techniques now may be applied to the NFP firms. The disadvantage is that (using the pricing equation) we cannot separately identify differences in goals between FP and NFP firms from differences in costs between the two forms. ${ }^{12}$ Hereafter, we will speak of "behavioral" marginal costs, which we will denote $\frac{\partial C^{B}}{\partial D}$, meaning $\frac{\partial C}{\partial D}$ for FP and $\frac{\partial C}{\partial D}+\frac{\partial U}{\partial D}$ for NFP.

Multi-plant firms (called multihospital systems) are common in this industry, so we account for substitution among plants and the coordination of pricing. Let $\Theta$ be a $J \times J$ matrix with $\Theta_{j k}=1$ if hospitals $j$ and $k$ have the same owner and $\Theta_{j k}=0$ otherwise. Under our maintained Bertrand assumption, the pricing equation for hospital $j$, part of a multihospital system, is then:

$$
0=D_{j}+\left(p_{j}-\frac{\partial C_{j}^{B}}{\partial D_{j}}\right) \frac{\partial D_{j}}{\partial p_{j}}+\sum_{j^{\prime} \text { sameowner }}\left(p_{j^{\prime}}-\frac{\partial C_{j^{\prime}}^{B}}{\partial D_{j^{\prime}}}\right) \frac{\partial D_{j^{\prime}}}{\partial p_{j}}
$$

Denote by $\left[\frac{\partial D}{\partial p}\right]$ the $J \times J$ demand derivative matrix. Stacking up these pricing equations, solving for price, and denoting element-by-element (Hadamard) matrix multiplication by $\circledast$ yields:

\footnotetext{
${ }^{12}$ NFP and FP firms are likely to have different costs because of their different access to capital markets. FPs can raise capital through equity issue, while NFPs cannot. However, NFPs can often issue tax-advantaged debt.
} 


$$
P=\left[\frac{\partial C^{B}}{\partial D}\right]+\left\{\Theta \circledast\left[\frac{\partial D}{\partial p}\right]\right\}^{-1} D
$$

We have now characterized demand and supply, which form the basis for our econometric model.

\section{Econometric Specification \& Estimation}

We proceed in several subsections. First, we impose functional forms, derive some useful results, and discuss identification for the consumer side of the model. Then, we briefly describe the functional form imposed on the producer side.

\subsection{Demand}

Observable consumer characteristics are denoted by $X$ and observable hospital characteristics are denoted by $Z$. There are $L$ observable consumer characteristics and $K$ observable hospital characteristics. Distance between a consumer's residence and the hospital is denoted $d_{i \rightarrow j}$. Unobservable producer characteristics consist of an unobserved quality, $\xi$.

Recall, consumers maximize effective utility functions of the form:

$$
V_{i j}=-\alpha_{i}^{p} p_{j} q_{i j}+v\left(q_{i j}, R_{i}, S_{j}\right)
$$

where $\alpha$ varies by insurer type and consumer characteristics. 


\subsubsection{Functional Form}

We use the following functional form for the effective utility function, $V$ :

$$
\begin{aligned}
V_{i j} & =-\tilde{\alpha}_{i}^{p} p_{j} q_{i j}+\frac{1}{\gamma}\left(\tilde{\beta}_{i} q\right)^{\gamma} \\
& +\tilde{\alpha}_{i}^{d} d_{i \rightarrow j}+\tilde{\alpha}_{i}^{d^{2}} d_{i \rightarrow j}^{2} \\
& +\sum_{k=1}^{K} Z_{j k} \tilde{\alpha}_{i k}+\xi_{j}+\epsilon_{i j} \\
\tilde{\beta}_{i} & =\exp \left(\sum_{l=1}^{L} X_{i l} \beta_{l}+\nu_{i}\right) \\
\tilde{\alpha}_{i}^{p} & =\exp \left(\alpha_{0}^{p}+\sum_{l=1}^{L} X_{i l} \alpha_{l}^{p}\right) \\
\tilde{\alpha}_{i}^{d} & =\alpha_{0}^{d}+\sum_{l=1}^{L} X_{i l} \alpha_{l}^{d} \\
\tilde{\alpha}_{i}^{d^{2}}= & \alpha_{0}^{d^{2}}+\sum_{l=1}^{L} X_{i l} \alpha_{l}^{d^{2}} \\
\tilde{\alpha}_{i k}= & \alpha_{0}+\sum_{l=1}^{L} X_{i l} \alpha_{l k}
\end{aligned}
$$

Here $\epsilon_{i j}$ is an i.i.d. Weibull random variable. In much of the previous literature, the equivalents of our $\alpha$ and $\beta$ coefficients have been modeled using random coefficients methods (beginning with Berry et al., 1995). Absent individual heterogeneity, popular discrete consumer choice models have the undesirable property of a fixed relationship between market 
shares and own and cross price elasticities of demand (see Berry, 1994). ${ }^{13}$ With aggregate data, individual heterogeneity can be introduced via random coefficients.

However, the observability of consumer-level characteristics, especially distance, obviates much of the rationale for including these effects. The nature of our data, with detailed information on individuals, allows us to explicitly account for observable individual heterogeneity. Distance in particular has been shown to be one of the most important determinants of choice of hospital. ${ }^{14}$ In our model hospitals physically close to one another have much higher cross-price elasticities than do hospitals far apart, breaking the inflexible relationship between market share and elasticity. Separately, the specification, even as it is, is extremely computationally burdensome, given the nearly 1 million observations used to estimate the over 400 parameters of the discrete choice model,

\subsubsection{Consumption and Indirect Effective Utility}

From this function, the optimal quantity which would be consumed by $i$ were he to go to $j$ is:

$$
q_{i j}^{*}=\beta_{i}^{\frac{\gamma}{1-\gamma}} \alpha_{i}^{\frac{1}{\gamma-1}} p_{j}^{\frac{1}{\gamma-1}}
$$

It is also easy to solve for the indirect utility of choosing hospital $j$ :

\footnotetext{
${ }^{13}$ This is certainly true of the logit model, which we use, but is due to the assumption that unobservable consumer tastes are distributed i.i.d., not any assumption about the specific form of their distribution.

${ }^{14}$ This is true both in the more recent structural literature and in an older hospital demand literature (see a partial review in Gaynor and Vogt, 2000).
} 


$$
\begin{aligned}
V_{i j}^{*} & =\left(\frac{1-\gamma}{\gamma}\right) \beta_{i}^{\frac{\gamma}{1-\gamma}} \alpha_{i}^{\frac{\gamma}{\gamma-1}} p_{j}^{\frac{\gamma}{\gamma-1}} \\
& +\tilde{\alpha}_{i}^{d} d_{i \rightarrow j}+\tilde{\alpha}_{i}^{d^{2}} d_{i \rightarrow j}^{2} \\
& +\sum_{k=1}^{K} Z_{j k} \tilde{\alpha}_{i} k+\xi_{j}+\epsilon_{i j}
\end{aligned}
$$

However, to reflect the fact that information is acquired during a hospital stay about the consumer's need for care, we will assume that $\nu_{i}$ is independent of $\epsilon$ and unobservable to both the demand and supply sides of the market before the choice of hospital is made. Expected indirect utility becomes:

$$
\begin{aligned}
E V_{i j}^{*} & =\left(\frac{1-\gamma}{\gamma}\right) E\left(\beta_{i}^{\frac{\gamma}{1-\gamma}}\right) \alpha_{i}^{\frac{\gamma}{\gamma-1}} p_{j}^{\frac{\gamma}{\gamma-1}} \\
& +\tilde{\alpha}_{i}^{d} d_{i \rightarrow j}+\tilde{\alpha}_{i}^{d^{2}} d_{i \rightarrow j}^{2} \\
& +\sum_{k=1}^{K} Z_{j k} \tilde{\alpha}_{i} k+\xi_{j}+\epsilon_{i j}
\end{aligned}
$$

Now, assuming that $\nu_{i}$ is identically distributed among consumers, the expectation, $E\left(\exp \left(\frac{\gamma}{1-\gamma} \nu_{i}\right)\right)$, is simply absorbed into the intercept in $\tilde{\beta}_{i}$. The empirical implication of this assumption is that there is no stochastic component to $\tilde{\beta}_{i}$ in the hospital choice equation, but there is such a component in the quantity determination equation. 


\subsubsection{Indirect Effective Utility and Expenditure}

In the model we presented in section 2 , we assumed that we observe the price of care at each hospital and the quantity of care demanded by each consumer. Neither of these things is true in our data. What we observe is list expenditures for each patient ("charges") — the expenditures which would apply were they to pay list prices. In addition, we observe the average ratio of actual expenditures at a hospital to the list expenditures (see equation 38 below). What we can make from this is an estimate of actual expenditures for each patient. Needless to say, this likely introduces measurement error. In addition, we do not really want to know expenditure by each consumer, we want to know the price paid and the quantity consumed by each patient.

In the data, we observe neither $p$ nor $q$. We observe only $p_{j} q_{i j}^{*}$ for the hospital actually chosen. This makes calculation of the first term of equation 20 problematic. However, since

$p_{j} q_{i j}^{*}=\beta_{i}^{\frac{\gamma}{1-\gamma}} \alpha_{i}^{\frac{1}{\gamma-1}} p_{j}^{\frac{\gamma}{\gamma-1}}$, the first term of equation 20 is $\frac{1-\gamma}{\gamma} \alpha_{i}^{p} p_{j} q_{i j}^{*}$. So, if $p_{j} q_{i j}^{*}$ were to be known for each $i$ and $j$, then $\frac{1-\gamma}{\gamma} \alpha_{i}^{p}$ would be estimable. Now, only $p_{j} q_{i j}^{*}$ for the chosen $j$ is data, so we turn to the question of constructing $p_{j} q_{i j}$ for the unchosen $j$.

Consider that, as things are parameterized now:

$$
\begin{aligned}
\ln p_{j} q_{i j}^{*} & =\frac{\gamma}{1-\gamma} \ln \tilde{\beta}_{i}+\frac{\gamma}{\gamma-1} \ln p_{j}+\frac{1}{\gamma-1} \ln \tilde{\alpha}_{i}^{p} \\
& =\sum_{j} \chi_{i \rightarrow j} \frac{\gamma}{1-\gamma} \ln p_{j} \\
& +\frac{1}{\gamma-1} \sum_{l} X_{i l}\left(\gamma \beta_{l}+\alpha_{l}^{p}\right)+\left(\gamma \nu_{i}\right)
\end{aligned}
$$


If we have $p_{j} q_{i j}$ and wish to calculate $p_{j^{\prime}} q_{i j^{\prime}}^{*}$, the formula is:

$$
\begin{aligned}
p_{j^{\prime}} q_{i j^{\prime}}^{*} & =p_{j} q_{i j}^{*} \exp \left(\frac{\gamma}{\gamma-1}\left(\ln p_{j^{\prime}}-\ln p_{j}\right)\right) \\
& =p_{j} q_{i j}^{*}\left(\frac{p_{j^{\prime}}}{p_{j}}\right)^{\frac{\gamma}{\gamma-1}}
\end{aligned}
$$

Since $p_{j}$ is unobserved, equation 22 can only be estimated by specifying $\frac{\gamma}{\gamma-1} \ln p_{j}$ as a set of dummy variables. Since $X$ will contain a constant, these dummies can identify $\left(\frac{\gamma}{\gamma-1}\left(\ln p_{j}-\ln p_{0}\right)\right)$, where 0 is the omitted contrast hospital. This, however, is exactly the information necessary to calculate $p_{j} q_{i j}^{*}$ for each $j$ given that we observe $p_{j} q_{i j}^{*}$ for one $j$.

\subsubsection{Identification}

Since we observe only $p_{j} q_{i j}$ and not $p$ and $q$ separately, separate identification of $\alpha$ and $\gamma$ is difficult. In equation 22 , only $\frac{\gamma}{1-\gamma}\left(\ln p_{j}-\ln p_{0}\right)$ is identified. This does provide enough information to create $p_{j} q_{i j}$ for each $j$, but not enough to separate $p$ from $q$. It is easy to show that:

$$
\begin{aligned}
E V_{i j}^{*} & =\left(\frac{1-\gamma}{\gamma}\right) \alpha_{i} p_{j} E\left(q_{i j}\right) \\
& +\tilde{\alpha}_{i}^{d} d_{i \rightarrow j}+\tilde{\alpha}_{i}^{d^{2}} d_{i \rightarrow j}^{2} \\
& +\sum_{k=1}^{K} Z_{j k} \tilde{\alpha}_{i} k+\xi_{j}+\epsilon_{i j}
\end{aligned}
$$

So, estimation of equation 18 can identify $\frac{1-\gamma}{\gamma} \alpha_{i}$. But, we cannot separately identify 
$\alpha$ and $\gamma$. To deal with this, we will assume that $\gamma=\infty$, equivalently that the elasticity of demand for hospital care, once a consumer has arrived at a hospital, is zero. This is a reasonable assumption, based on the results of the RAND Health Insurance Experiment. The findings of that experiment included a very low price elasticity of demand for hospital care and a finding that virtually all of the reduction in the consumption in health care arising from a price increase occurred as a result of a reduction in the probability of obtaining care: virtually none of it resulted from a reduction in the quantity of care used conditional on having obtained it (Manning et al., 1987; Newhouse, 1993; Keeler et al., 1988). With this assumption in place, equation 22 becomes:

$$
\begin{aligned}
\ln p_{j} q_{i j}^{*} & =\sum_{j} \chi_{i \rightarrow j} \ln p_{j} \\
& +\sum_{l} X_{i l} \beta_{l}+\nu_{i}
\end{aligned}
$$

Beginning with this equation, we may separate price and quantity. Once it is estimated, we may fix $X_{i}$ at some value (we take means) and define $E\left(q_{i}\right)=1$ for that $X_{i}$. Then, equation 25 can be used to predict expected expenditures for this "standard" discharge, giving a measure of $p$ for each hospital.

\subsubsection{Estimating Equations}

As we describe above, the demand model has the utility for consumer $i$ of going to hospital $j$ as a function of hospital characteristics, $K$ observable and one unobservable, and of interactions between hospital and $L$ observable consumer characteristics. We rewrite and slightly 
generalize equation 24, absorbing the hospital's price into $Z_{j}$ and $\hat{q}$ into $X_{i}$ :

$$
\begin{aligned}
E V_{i j}^{*} & =\sum_{k=1}^{K} Z_{j k} \alpha_{i k}+\xi_{j} \\
& +\rho d_{i \rightarrow j}+\sum_{l=1}^{L} \rho_{l}^{X} X_{i l} d_{i \rightarrow j}+\sum_{k=1}^{K} \rho_{k}^{Z} Z_{j} k d_{i \rightarrow j} \\
& +\rho^{2} d_{i \rightarrow j}^{2}+\sum_{l=1}^{L} \rho_{l}^{2 X} X_{i l} d_{i \rightarrow j}^{2}+\sum_{k=1}^{K} \rho_{k}^{2 Z} Z_{j} k d_{i \rightarrow j}^{2}+\epsilon_{i j} \\
\alpha_{i k} & =\alpha_{0 k}+\sum_{l=1}^{L} X_{i l} \alpha_{l k}
\end{aligned}
$$

Berry et al. (1998) discuss the estimation of models in this class using micro data. First, we substitute equation 27 into 26 to get:

$$
\begin{aligned}
E V_{i j}^{*} & =\sum_{k=1}^{K} \alpha_{0 k} Z_{j k}+\sum_{k=1}^{K} \sum_{l=1}^{L} X_{i l} Z_{j k} \alpha_{l k}+\xi_{j} \\
& +\rho d_{i \rightarrow j}+\sum_{l=1}^{L} \rho_{l}^{X} X_{i l} d_{i \rightarrow j}+\sum_{k=1}^{K} \rho_{k}^{Z} Z_{j} k d_{i \rightarrow j} \\
& +\rho^{2} d_{i \rightarrow j}^{2}+\sum_{l=1}^{L} \rho_{l}^{2 X} X_{i l} d_{i \rightarrow j}^{2}+\sum_{k=1}^{K} \rho_{k}^{2 Z} Z_{j} k d_{i \rightarrow j}^{2}+\epsilon_{i j}
\end{aligned}
$$

It is tempting to estimate equation 28 using a logit maximum likelihood routine. However, under virtually any oligopoly model of price setting, $p_{j}$ (one of the $Z_{j}$ ) will be correlated with $\xi_{j}$, part of the error. So, simultaneous equations bias will render the estimates inconsistent.

Berry et al. (1998) suggest, among other possibilities, the following solution. Rewrite (28) as a "mean" level of utility of hospital $j, \delta_{j}$, and deviations from the mean: 


$$
\begin{aligned}
E V_{i j}^{*} & =\sum_{k=1}^{K} Z_{j k} \overline{\alpha_{k}}+\xi_{j}+\sum_{k=1}^{K} \sum_{l=1}^{L}\left(X_{i l}-\overline{X_{i l}}\right) Z_{j k} \alpha_{l k} \\
& +\rho d_{i \rightarrow j}+\sum_{l=1}^{L} \rho_{l}^{X} X_{i l} d_{i \rightarrow j}+\sum_{k=1}^{K} \rho_{k}^{Z} Z_{j} k d_{i \rightarrow j} \\
& +\rho^{2} d_{i \rightarrow j}^{2}+\sum_{l=1}^{L} \rho_{l}^{2 X} X_{i l} d_{i \rightarrow j}^{2}+\sum_{k=1}^{K} \rho_{k}^{2 Z} Z_{j} k d_{i \rightarrow j}^{2}+\epsilon_{i j} \\
\overline{\alpha_{k}} & =\alpha_{0 k}+\sum_{l=0}^{L} \overline{X_{i l}} \alpha_{l k}
\end{aligned}
$$

And then as:

$$
\begin{aligned}
E V_{i j}^{*} & =\delta_{j}+\sum_{k=1}^{K} \sum_{l=1}^{L}\left(X_{i l}-\overline{X_{i l}}\right) Z_{j k} \\
& +\rho d_{i \rightarrow j}+\sum_{l=1}^{L} \rho_{l}^{X} X_{i l} d_{i \rightarrow j}+\sum_{k=1}^{K} \rho_{k}^{Z} Z_{j} k d_{i \rightarrow j} \\
& +\rho^{2} d_{i \rightarrow j}^{2}+\sum_{l=1}^{L} \rho_{l}^{2 X} X_{i l} d_{i \rightarrow j}^{2}+\sum_{k=1}^{K} \rho_{k}^{2 Z} Z_{j} k d_{i \rightarrow j}^{2}+\epsilon_{i j} \\
\delta_{j} & =\sum_{k=0}^{K} Z_{j k} \overline{\alpha_{k}}+\xi_{j}
\end{aligned}
$$

Still following Berry et al. (1998), equations 29 and 30 suggest a two-step estimation strategy. First, (29) can be estimated by logit maximum likelihood including a dummy variable for each hospital and covariates for all interactions among the consumer and hospital characteristics. Then, after the $\delta_{j}$ have been estimated, they can be used as left-handside variables in (30) to obtain estimates of $\overline{\alpha_{k}}$. This second stage regression will involve 
instrumenting for $p_{j}$, since the same endogeneity which makes maximum likelihood on (28) undesirable would also militate against using OLS on (30).

\subsubsection{Instruments}

To find instruments for the demand equation, we look to the supply side of the market, in the form of the pricing equation (for a single firm):

$$
p_{j}=\frac{\partial C^{B}}{\partial D}\left(D_{j}, W_{j}, Z_{j}, \zeta_{j}\right)-\frac{D_{j}}{\frac{\partial D_{j}}{\partial p_{j}}}
$$

Of the variables in this equation, $D_{j}, W_{j}$, and $\frac{\partial D_{j}}{\partial p_{j}}$ do not appear on the demand side. However, $D_{j}$ and $\frac{\partial D_{j}}{\partial p_{j}}$ are themselves endogenous, as both depend upon price. So, as instruments for the demand side, we have $W_{j}$ and any exogenous variables which shift $D_{j}$ and $\frac{\partial D_{j}}{\partial p_{j}}$. Now, we know that, in expectation:

$$
\begin{aligned}
\widehat{D_{j}} & =\sum_{i=1}^{I} \operatorname{Pr}\{i \rightarrow j \mid \mathbf{p}, \xi\} E\left(q_{i}\right) \\
\frac{\widehat{\partial D_{j}}}{\partial p_{j}} & =\sum_{i=1}^{I} \frac{\partial \operatorname{Pr}\{i \rightarrow j \mid \mathbf{p}, \xi\}}{\partial p_{j}} E\left(q_{i}\right)
\end{aligned}
$$

Evidently, $\operatorname{Pr}\{i \rightarrow j \mid \mathbf{p}, \xi\}$ depends upon $p_{j}$ and on $\xi_{j}$, so it is endogenous. However, it also depends upon the distances between consumer $i$ and all of the hospitals. These distances are presumed exogenous. In addition, $\operatorname{Pr}\{i \rightarrow j \mid \mathbf{p}, \xi\}$ depends upon the interactions among exogenous consumer and producer characteristics. These observations suggest an 
instrumenting strategy. We can calculate, $D_{j}^{I V}$ by evaluating (32) at $\xi=0$ and omitting all terms involving price, so that $D_{j}^{I V}$ depends only upon exogenous distances and interactions between consumer and producer characteristics. In a similar manner, an instrument for $\frac{D_{j}}{\frac{\partial D_{j}}{\partial p_{j}}}$ can be calculated. ${ }^{15}$ These instruments are similar to Berry et al. (1998), who use predictions of the markup as instruments.

\subsection{Supply}

Recall the pricing equation:

$$
P=\left[\frac{\partial C^{B}}{\partial D}\right]+\left\{\Theta \circledast\left[\frac{\partial D}{\partial p}\right]\right\}^{-1} D
$$

After estimating the demand side, we can calculate

$$
\left\{\Theta \circledast\left[\frac{\partial D}{\partial p}\right]\right\}^{-1} D .
$$

Representative elements of $\left[\frac{\partial D}{\partial p}\right]$ are calculated as follows:

\footnotetext{
${ }^{15}$ Before estimating equation 30, we do not know the value of $\bar{\alpha}$. We create $D^{I V}$ and ${\frac{D_{j}}{\frac{\partial D_{j}}{\partial p_{j}}}}^{I V}$ by first setting $\delta=0$ and the parameters on price in the interacted logit to zero. Then, with estimates of $\bar{\alpha}$ in hand, we calculate the instruments as described above.
} 


$$
\begin{aligned}
& \frac{\partial D_{j}}{\partial p_{j}}=\sum_{i=1}^{I} \operatorname{Pr}\{i \rightarrow j\}(1-\operatorname{Pr}\{i \rightarrow j\}) q_{i j} \\
& \frac{\partial D_{j}}{\partial p_{j}^{\prime}}=\sum_{i=1}^{I} \operatorname{Pr}\{i \rightarrow j\} \operatorname{Pr}\left\{i \rightarrow j^{\prime}\right\} q_{i j}
\end{aligned}
$$

Thus, our estimating equation for the supply side is:

$$
\begin{aligned}
& P-\left\{\Theta \circledast\left[\frac{\partial D}{\partial p}\right]\right\}^{-1} D=\left[\frac{\partial C^{B}}{\partial D}\right] \\
& P-\left\{\Theta \circledast\left[\frac{\partial D}{\partial p}\right]\right\}^{-1} D=\omega_{0}+D \omega_{D}+W \omega_{W}+Z \omega_{Z}+\zeta
\end{aligned}
$$

$D$ is endogenous, but the other variables are assumed exogenous. Again, $D_{j}^{I V}$ is used for instrumenting, as it depends only upon presumed exogenous location.

\subsection{Estimation Procedure}

The estimation proceeds in four steps. First, the expenditure equation (25) is estimated via OLS. From this $p$ and $q$ are backed out and used in the next step, which is the estimation of the multinomial logit demand system (29) by maximum likelihood. The $\delta$ recovered from this estimation are then used as left-hand-side variables in the estimation of the average

effects of $p$ and $Z$ on demand in (30), estimated by two stage least squares. Finally, the 
parameters from the demand estimation are used to calculate the left-hand-side of (37), and it is estimated via two stage least squares.

\section{Data}

The California Office of Statewide Health Planning and Development (OSHPD) ${ }^{16}$ maintains a variety of datasets on various aspects of health care in California. Each of the particular datasets we draw upon, and the criteria for selecting data subsets is described below.

\subsection{Sources}

We draw data for 1995 from three of the datasets maintained by OSHPD: the annual discharge data, the annual financial data, and the quarterly financial data. 1995 is a good year to examine because it is during the time period for which previous studies have found price competition to be present in the hospital sector in California and it is two years before the occurrence of the merger whose effects we simulate.

\subsubsection{Discharge Data}

Each non-Federal hospital in California is required to submit discharge data to OSHPD. For each patient discharge during the year, a record is generated.

Among the items collected for each discharge are patient demographics (age, sex, race), diagnosis (several DRG and ICD9-CM codes), ${ }^{17}$ treatment (several ICD9-CM codes), an

\footnotetext{
${ }^{16}$ http://www.oshpd.cahwnet.gov

${ }^{17}$ DRG (diagnosis related groups) and ICD9 (International Classification of Disease) codes are codes used by all private and public insurers in the U.S. for recording diagnoses. The ICD9 also includes (separate) codes for treatments.
} 
identifier for the hospital at which the patient sought care, the patient's zipcode of residence, and charges.

Charges are the "list" price for the hospital stay. They are typically presented on a hospital bill as a sum of items multiplied by a list price for each item. ${ }^{18}$ The charges which appear on a patient's discharge record are a poor proxy for the transaction price paid to the hospital, especially in recent years. Over time, reimbursement practices have evolved away from insurers more-or-less paying hospital charges. Most insurers negotiate with hospitals over payments which are reductions from charges. ${ }^{19}$ As a consequence, charges per se cannot be used as a measure of transaction price; although, given the way they are calculated they are related to the amount of care which a patient consumes.

In addition to the above information, there is a field describing, in general terms, the patient's health insurance information. The field distinguishes among Medicare, Medicaid, Blue Cross, HMO, PPO, other private insurance, self pay, and a variety of smaller categories.

\subsubsection{Financial Data}

Annual financial disclosures are submitted at each fiscal year and whenever a hospital changes ownership. Since these disclosures follow hospital fiscal years, they are not in sync with calendar years or even with each other.

These reports contain quite extensive information on each hospital's costs, revenues, capital, physical plant, payroll, outputs, and intermediate production goods, as well as detailed

\footnotetext{
${ }^{18}$ The line-item bill is not observable to us, only the total charges are.

${ }^{19}$ At the time of our data, in California, there were a variety of different reimbursement arrangements among insurers and hospitals. Some insurers pay a negotiated discount off charges. Some pay a negotiated flat per day (called a "per diem"). Some pay an amount per discharge, based upon the diagnosis. Some pay a flat ex ante amount per insured, per year — whether or not the insured goes to the hospital or not.
} 
information on ownership and on the type of care the hospital provides (short-term, longterm,psychiatric,etc). From these data, we will use information on location of the hospital, ownership of the hospital, type of care provided by the hospital, whether the hospital is a teaching hospital or not, and wages. Since we are only using hospital characteristics, which are fixed, and wages, which change slowly over the relevant time period, the lack of sync regarding hospital fiscal years is not important for our purposes.

\subsubsection{Quarterly Financial Data}

Quarterly financial disclosures are submitted by calendar quarters, so that they are in sync both with the discharge data and with one another.

For the most part, the quarterly financial data are a subset of the annual data. Information on costs, revenues, and outputs comprise most of the fields. There are, however, a few data elements in the quarterly data which do not appear in the annual data, which we will use.

"Gross revenues," "net revenues," and "contractual discounts" are broken out in these data by insurance categories. We will use these variables to map from the "charges" for each consumer $i$ in the discharge data to a variable we construct called "net charges," which we will denote $p_{j} q_{i}$. The calculation is:

$$
p_{j} q_{i}=\operatorname{charges}_{i} \frac{G R I_{j}^{\text {oth } 3^{\text {rd }}}+G R O_{j}^{\text {oth } 3^{\text {rd }}}-D E D_{j}^{\text {oth } 3^{\text {rd }}}}{G R I_{j}^{\text {oth } 3^{\text {rd }}}+G R O_{j}^{\text {oth } 3^{\text {rd }}}}
$$

The symbols represent (GRI) gross inpatient revenue from "other third party" insurers 
Table 1: Distribution of Discharges by Insurance

\begin{tabular}{r|r|r} 
Insurance Type & Frequency & Percent \\
\hline Medicare & $1,023,160$ & $28.2 \%$ \\
Medicaid & 960,811 & $26.5 \%$ \\
HMO & 780,801 & $21.5 \%$ \\
PPO & 336,913 & $9.3 \%$ \\
Other Pvt & 145,161 & $4.0 \%$ \\
Self Pay & 135,406 & $3.7 \%$ \\
BC / BS & 74,243 & $2.0 \%$ \\
Various Gvt & 86,968 & $2.4 \%$ \\
Various Indigent & 85,678 & $2.4 \%$
\end{tabular}

(private 3rd party insurers, roughly), (GRO) gross outpatient revenues from these insurers and (DED) contractual deductions from these revenues. We sum the quarterly data to annual levels, since the quarterly data are quite volatile.

\subsection{Selections}

For 1995, there are a total of 3.6 million patient discharges. These break down among insurance plans as in Table 1. For our principal analysis, we will use the discharges in the HMO, PPO, Other Private, Self Pay, and Blue Cross / Blue Shield categories. These amount to 1.47 million discharges, or about $41 \%$ of the total discharges in the state. Our motivation in making these choices is that for patients in these categories, some entity, either the patient or the insurance company, is making explicit choices among hospitals, based, at least in part, on price. $^{20}$ In the case of the various insurance categories, insurers have discretion both over which hospitals to include in their networks of approved providers and via any channeling of patients to less expensive hospitals.

\footnotetext{
${ }^{20}$ To some unobserved extent, self-pay patients are "really" charity patients from whom no collection is expected to be possible.
} 
More of these observations are lost to some subsequent selections. Only patients seeking care at one of the analysis hospitals (described below) are included. Only patients with a diagnosis (DRG) with a frequency of at least 1,000 are included. Patients with missing values for any of the variables used in any of our analyses or with charges less than 500 or greater than 500,000 are excluded, as are consumers with lengths of stay of 0 or of greater than 30. After all the exclusions, there are 913,660 remaining observations. ${ }^{21}$

There are 593 total hospitals in the financial data. Of these, 420 are short-term general hospitals (this excludes such institutions as psychiatric hospitals, children's hospitals, rehabilitation hospitals, and other specialty institutions). There are further selections to the hospitals since some have either missing or useless quarterly financial data (some hospitals had larger deductions from revenue than they had gross revenue, for example). ${ }^{22}$ In addition, hospitals associated with staff model HMOs (most notably Kaiser) do not have meaningful prices, since they are vertically integrated with a single insurer; hence, these hospitals are excluded. ${ }^{23}$ Finally, we exclude hospitals with fewer than 100 discharges for the year. This leaves us with an analysis sample of 913,660 discharges and 374 hospitals.

\subsection{Location}

As we describe below, the most important source of identifying variation for our estimation is the relative distance between a consumer and the various hospitals in his choice set. To

\footnotetext{
${ }^{21}$ As can be observed from Table 1, most of the reduction (1.5 million discharges) in the analysis sample comes from eliminating discharges with a public insurer (Medicare, Medicaid), another 600,000 discharges are eliminated due to being treated at a specialty hospital as opposed to a short term general hospital.

${ }^{22}$ Hospitals with strange data for these variables are disproportionately small hospitals, so many are eliminated by a later criterion anyway.

${ }^{23}$ Notice that this means that we are ignoring a possible avenue of substitution: from our sample of hospitals to Kaiser hospitals via a change in insurer.
} 
calculate these distances, we obtained longitude and latitude coordinates for each California zip code appearing in our data from census files. For the hospitals, we obtained each one's longitude and latitude by using the street address available on the financial data and the web site www.MapsOnUs.com, run by Etak, a geographical information systems firm. Great circle distances are then easily calculated from each zip code's coordinates to each hospital.

We construct several variables which we will use in our analysis. The technology index is the sum over dummy variables for the presence of some 28 technologies reported in the annual financial data (things like presence of an MRI, open heart surgical suite, etc). The wage index is a Paasche wage index calculated relative to the average hospital over 10 job classifications (classifications like registered nurse, orderly, etc). The dummy for teaching status takes on a value of one for hospitals with a program to train resident physicians.

Table 2 contains variable descriptions and descriptive statistics.

\section{Results}

There are four estimations to discuss, the separation of price and quantity, the large discrete choice demand estimation which produces $\delta$, the estimation of the determinants of $\delta$, and the pricing equation.

\subsection{Prices and Quantities}

Equation 25 is estimated on the set of 913,660 discharges from the 374 analysis hospitals. The regression is run with log net expenditure as the left hand side variable. Right hand side variables are the 374 hospital dummies, 13 dummy variables for age categories, 1 
Table 2: Variable Descriptions

\begin{tabular}{|c|c|c|c|}
\hline Name & Description & Mean & Std dev \\
\hline $\mathrm{X}$ & Consumer Characteristics & & \\
\hline$\hat{q}$ & E(quantity)from eqn 25 & 1.24 & 1.61 \\
\hline $\mathrm{HMO}$ & Membership in HMO & 0.50 & 0.50 \\
\hline $\mathrm{PPO}$ & Membership in PPO & 0.31 & 0.46 \\
\hline unsched & Unscheduled admission & 0.53 & 0.50 \\
\hline $\mathrm{X}$ & Distance & & \\
\hline $\begin{array}{l}d_{i \rightarrow j} \\
d_{i \rightarrow j}^{2}\end{array}$ & $\begin{array}{r}\text { Distance to (chosen) hospital (miles) } \\
\text { Distance squared }\end{array}$ & 11.56 & 27.78 \\
\hline $\mathrm{Z}$ & Hospital Characteristics & & \\
\hline $\mathrm{P}$ & E(Price) from eqn 25 & 4696 & 1603 \\
\hline FP & For-profit status & 0.28 & 0.45 \\
\hline NFP & Not-for-profit status & 0.52 & 0.50 \\
\hline Teach & Teaching hospital & 0.21 & 0.41 \\
\hline Tech & Technology index & 15.02 & 6.06 \\
\hline SYS & Multihospital system member & 0.49 & 0.50 \\
\hline W & Input Prices & & \\
\hline$W$ & Wage index & 0.99 & 0.15 \\
\hline
\end{tabular}


dummy variable for sex categories, 5 dummy variables for race categories, 305 variables for DRG dummies, 3 dummy variables for "severity," 3 dummy variables for type of admission (scheduled, unscheduled, newborn, unknown), 24 dummy variables for the number of other diagnoses (the number of other illnesses the consumer has in addition to the one for which he was admitted), and interactions between 23 variables for major diagnostic category (a more granular measure of diagnosis) and the age, sex, race, severity, type of admission, and other diagnoses dummies. There are 1792 right-hand-side variables total. The $R^{2}$ for the equation is 0.81 .

We can now calculate price and quantity as described previously using the estimates from this regression. The average hospital price is $\$ 4,696$ with a standard deviation of $\$ 1,603$ among the 374 hospitals. Government hospitals have the highest prices (recall, on private-pay patients), at $\$ 4957$ per adjusted discharge. FP hospitals have higher prices $(\$ 4793)$ than do NFP hospitals $(\$ 4545)$. Quantity per consumer is highest at NFP at 1.24 adjusted discharges per discharge. FPs have 1.20 adjusted discharges per discharge, and government hospitals have $1.11 .^{24}$

\subsection{Demand Logit}

The demand logit contains a full set of hospital dummies (373 dummy variables for the 374 hospitals). In addition it contains a full set of interactions among the 5 hospital characteristics and the 4 consumer characteristics. These variables have been previously described in Table 2. There are 20 interactions between hospital and consumer characteristics. In

\footnotetext{
${ }^{24}$ These figures are means over hospital means; thus, so they are not inconsistent with the overall mean reported in Table 2
} 
Table 3: MNL Results

\begin{tabular}{r|r|r} 
Variable & Estimate & Standard Error \\
\hline P $\hat{q}$ & -0.0261 & 0.0005 \\
P HMO & -0.157 & 0.002 \\
P PPO & -0.121 & 0.003 \\
P unsch & 0.006 & 0.002 \\
FP $\hat{q}$ & 0.082 & 0.004 \\
FP HMO & 0.721 & 0.016 \\
FP PPO & 0.787 & 0.018 \\
FP unsch & -0.195 & 0.013 \\
NFP $\hat{q}$ & 0.046 & 0.003 \\
NFP HMO & 0.617 & 0.013 \\
NFP PPO & 0.695 & 0.015 \\
NFP unsch & -0.216 & 0.011 \\
Teach $\hat{q}$ & 0.040 & 0.002 \\
Teach HMO & 0.285 & 0.008 \\
Teach PPO & 0.078 & 0.009 \\
Teach unsch & 0.052 & 0.006 \\
Tech $\hat{q}$ & 0.009 & 0.0002 \\
Tech HMO & 0.048 & 0.001 \\
Tech PPO & 0.034 & 0.001 \\
Tech unsch & -0.028 & 0.001
\end{tabular}

addition, we include distance, distance squared, and interactions between these and both consumer and hospital characteristics, for an additional 20 parameters.

The multinomial logit estimation includes 913,660 observations, 374 choices, and 413 parameters. The results of this estimation appear in Tables 3 and 4 (omitting the coefficients on the 373 hospital dummies).

The results in Table 3 are, for the most part, intuitive. Consumers who will consume more care are more price sensitive. $\mathrm{HMO}$ and PPO consumers are more price sensitive, the increase in the price coefficient being about $13 \%$ and $10 \%$ respectively. Higher demanding consumers (perhaps "sicker") value teaching hospitals and high-tech hospitals more. People 
Table 4: MNL Results, continued

\begin{tabular}{r|r|r} 
Variable & Estimate & Standard Error \\
\hline$d_{i \rightarrow j}$ & -23.92 & 0.05 \\
$d_{i \rightarrow j}^{2}$ & 3.15 & 0.01 \\
$d_{i \rightarrow j} \hat{q}$ & 0.717 & 0.003 \\
$d_{i \rightarrow j}^{2} \hat{q}$ & -0.119 & 0.001 \\
$d_{i \rightarrow j}$ HMO & -6.517 & 0.018 \\
$d_{i \rightarrow j}^{2}$ HMO & 1.023 & 0.003 \\
$d_{i \rightarrow j}$ PPO & -2.860 & 0.017 \\
$d_{i \rightarrow j}^{2}$ PPO & 0.412 & 0.003 \\
$d_{i \rightarrow j}$ unsch & -1.909 & 0.014 \\
$d_{i \rightarrow j}^{2}$ unsch & 0.314 & 0.003 \\
$d_{i \rightarrow j} \mathrm{P}$ & 0.596 & 0.005 \\
$d_{i \rightarrow j}^{2} \mathrm{P}$ & -0.069 & 0.002 \\
$d_{i \rightarrow j} \mathrm{FP}$ & 0.621 & 0.035 \\
$d_{i \rightarrow j}^{2} \mathrm{FP}$ & -0.080 & 0.008 \\
$d_{i \rightarrow j}$ NFP & 0.280 & 0.029 \\
$d_{i \rightarrow j}^{2}$ NFP & -0.022 & 0.007 \\
$d_{i \rightarrow j}$ Teach & 4.06 & 0.019 \\
$d_{i \rightarrow j}^{2}$ Teach & -0.583 & 0.005 \\
$d_{i \rightarrow j}$ Tech & 0.048 & 0.002 \\
$d_{i \rightarrow j}^{2}$ Tech & -0.004 & 0.001
\end{tabular}

whose admissions are unscheduled are less price sensitive (and in Table 4, more distance sensitive). In addition, as indicated by the means of the hospital dummies $\left(\delta_{j}\right)$ by ownership class, FP and NFP hospitals are more attractive to consumers than government hospitals $\left(\bar{\delta}_{N F P}=1.65, \bar{\delta}_{F P}=1.83, \bar{\delta}_{\text {govt }}=-1.18\right)$.

\subsection{Average Utility}

Now, we turn to the estimation of the mean utility levels. Recall that we are estimating equation 30, the demand equation. The endogenous variable in the demand equation is price. Ownership, teaching, technology, and wages are exogenous. We use the exogenous location of 
Table 5: Demand Equation

\begin{tabular}{r|r|r} 
Variable & OLS & 2 SLS \\
\hline & & \\
& & \\
constant & -1.92 & 1.40 \\
& $(0.53)$ & $(1.84)$ \\
$\mathrm{P}$ & -0.52 & -1.22 \\
& $(0.08)$ & $(0.38)$ \\
$\mathrm{FP}$ & 3.16 & 3.15 \\
& $(0.36)$ & $(0.40)$ \\
$\mathrm{NFP}$ & 1.54 & 1.27 \\
& $(0.34)$ & $(0.40)$ \\
Teach & 0.22 & 0.67 \\
& $(0.32)$ & $(0.43)$ \\
tech & 0.25 & 0.25 \\
& $(0.02)$ & $(0.03)$ \\
\hline$R^{2}$ & 0.42 & \\
$N$ & 374 & 374
\end{tabular}

consumers and hospitals to derive our key instruments, $D_{j}^{I V}$, and $\frac{D_{j} I V}{\frac{\partial D_{j}}{\partial p_{j}}}$. Both variables are correlated with variables in the firm's pricing equation, the first because of scale economies and the second because of market power. The wage index provides an additional instrument, and the non-price characteristics of hospitals are presumed exogenous throughout. The results appear in Table 5. The column heads describe the estimation techniques as they are applied to equation 30 .

OLS produces an estimate of the coefficient on price of the "right" sign. However, as we move across the table and add instruments, the price coefficient becomes more negative. The coefficient of -1.22 on price (in thousands of dollars) corresponds to an average demand elasticity facing hospitals of -5.67. The elasticity is highest for FP firms, at -6.25 and lowest 
for government hospitals at -5.21. NFP hospitals on average face an elasticity of -5.54. As indicated by the estimates for the relevant dummy variables, on average, consumers prefer FP to NFP to government hospitals; they also prefer teaching and high tech hospitals.

The instruments for this regression performed quite well. The simple correlation between price and $\frac{D_{j}}{\frac{\partial D_{j}}{\partial p_{j}}}$ iV $0.11(P<0.03)^{25}$, and the simple correlation between price and the wage index is $0.15(P<0.01)$. In the first stage regression (in the appendix), both $W$ and ${\frac{D_{j}}{\partial D_{j}}}^{I V}$ are individually highly significant, with the "right" signs, while $D^{I V}$ is insignificant. The $F$ statistic for the first stage regression is 4.91 , yielding significance at less than the $1 \%$ level, and the $F$ statistic for the joint exclusion of the three price instruments is $6.54(P<0.01)$.

\subsection{Supply}

Estimates of equation 16 appear in Table 6. The instruments for this regression are the non-price hospital characteristics, $D^{I V}$, and squares and interactions of these. Both the left-hand-side variable and quantity, a right-hand-side variable, are measured in thousands. Recalling equation 37, we are recovering estimates of the parameters of behavioral marginal cost. The point estimates here indicate decreasing returns to scale for the government hospitals and increasing returns to scale for FP and NFP hospitals. The effect sizes are modest, and the scale economies are neither singly nor jointly significant at conventional levels.

We previously noted that FPs price on average $\$ 248$ higher than do NFPs. This difference is accounted for by differences in behavioral marginal costs and differences in markups.

\footnotetext{
${ }^{25} P$ here denotes $\mathrm{P}$-value.
} 
Table 6 reveals that the behavioral marginal cost intercept for FPs is about $\$ 950$ higher than it is for NFPs. This difference diminishes with expanding output, and at about 6000 adjusted discharges and above, the NFPs' behavioral marginal costs are higher. Six thousand discharges is a large hospital, but is within the range of the data. At sample means, FPs have behavioral marginal costs about $\$ 430$ higher than do NFPs. Average markups are $\$ 986$ for NFPs and $\$ 830$ for FPs. These represent a $22 \%$ markup on average for NFPs and a $17 \%$ markup for FPs.

The teaching and technology variables are of the "right" sign and the teaching dummy's coefficient is significant. The system variable indicates that members of multihospital systems enjoy marginal costs about $\$ 450$ lower than non-members.

Instrument performance is again good. ${ }^{26}$ The simple correlation between $D$ and $D^{I V}$ is $0.53(P<0.01)$, and the correlations between $D \times F P$ and $D^{I V} \times F P$ and $D \times N F P$ and $D^{I V} \times N F P$ are 0.66 and 0.75 , both $(P<0.01)$. The three first stage regressions each have $F$ statistics significant at better than $1 \%$ overall, and the exclusion restrictions for the instruments not in the second stage equations are rejected in all three equations at (much) better than the $1 \%$ level.

In terms of behavioral differences, the results indicate both lower pricing and lesser apparent scale diseconomies for NFPs compared to FPs. As we have indicated previously, we cannot separate these differences into cost and utility differences. In our model, behavioral differences with respect to merger analysis arise through behavioral scale economies: as a general rule, hospitals with greater scale economies will raise their prices more as a result

\footnotetext{
${ }^{26}$ Since the regressions are long, we don't report the entire set of estimates here.
} 
Table 6: Supply Equation

\begin{tabular}{|c|c|c|}
\hline Variable & OLS & 2SLS \\
\hline constant & $\begin{array}{c}0.21 \\
(0.62)\end{array}$ & $\begin{array}{r}0.56 \\
(0.68)\end{array}$ \\
\hline$W$ & $\begin{array}{c}3.06 \\
(0.63)\end{array}$ & $\begin{array}{r}2.70 \\
(0.68)\end{array}$ \\
\hline$D$ & $\begin{array}{c}-0.15 \\
(0.11)\end{array}$ & $\begin{array}{c}0.12 \\
(0.19)\end{array}$ \\
\hline$D \times F P$ & $\begin{array}{c}-0.08 \\
(0.13)\end{array}$ & $\begin{array}{c}-0.29 \\
(0.14)\end{array}$ \\
\hline$D \times N F P$ & $\begin{array}{c}0.08 \\
(0.13)\end{array}$ & $\begin{array}{c}-0.14 \\
(0.18)\end{array}$ \\
\hline$F P$ & $\begin{array}{c}0.88 \\
(0.30)\end{array}$ & $\begin{array}{c}1.06 \\
(0.42)\end{array}$ \\
\hline$N F P$ & $\begin{array}{c}-0.10 \\
(0.28)\end{array}$ & $\begin{array}{c}0.11 \\
(0.36)\end{array}$ \\
\hline Teach & $\begin{array}{c}0.91 \\
(0.22)\end{array}$ & $\begin{array}{c}0.93 \\
(0.24)\end{array}$ \\
\hline Tech & $\begin{array}{r}0.04 \\
(0.02)\end{array}$ & $\begin{array}{c}0.01 \\
(0.02)\end{array}$ \\
\hline$S Y S$ & $\begin{array}{r}-0.49 \\
(0.17) \\
\end{array}$ & $\begin{array}{r}-0.45 \\
(0.18) \\
\end{array}$ \\
\hline$R^{2}$ & 0.17 & \\
\hline$N$ & 374 & 374 \\
\hline
\end{tabular}


Table 7: Means by Ownership Class

\begin{tabular}{r|r|r|r} 
Variable & GVT & FP & NFP \\
\hline$\delta_{j}$ & -1.18 & 1.83 & 1.65 \\
$p_{j}$ & 4957 & 4793 & 4545 \\
Teach & 0.31 & 0.07 & 0.25 \\
Tech & 12.95 & 12.25 & 17.26 \\
$W$ & 0.98 & 0.99 & 1.03 \\
$S Y S$ & 0.23 & 0.59 & 0.54 \\
$D_{j}$ & 1186 & 1669 & 4449 \\
$q_{i}$ & 1.11 & 1.20 & 1.24 \\
Markup & 1260 & 830 & 986 \\
Elasticity & -5.21 & -6.25 & -5.54 \\
$\mathrm{~N}$ & 75 & 103 & 196
\end{tabular}

of a merger. Since, at point estimates, NFP hospitals do have lesser scale economies, our results are in the right "direction" for NFPs to raise their prices less in response to merger. We assess the size of this effect in the next section.

Last, for purposes of summary, Table 7 contains means by ownership class, including means of predicted variables. To recap, government hospitals have the highest prices (recall, on private-pay patients), at $\$ 4957$ per adjusted admission, and markups, at $\$ 1260$, as they as they face the least local competition. FP hospitals have higher prices than do NFP hospitals, even though FP hospitals face more competition, yielding lower markups. As indicated above, this difference in prices comes both from scale economies, NFPs are larger than are FPs, and through differences in behavioral marginal costs, NFPs act as if they have substantially lower marginal costs, on average. FP and NFP hospitals are more attractive to consumers than are government hospitals. NFPs are also more likely than are FPs to be teaching hospitals and to be high tech. 


\section{Merger Simulation}

To assess the implications for merger analysis of differences between FP and NFP hospitals, we simulate a 1997 merger using our estimated model. There is now a substantial literature on merger simulation in antitrust contexts (see, for example, the special issues introduced by Werden and Froeb, 2000; Muris, 1997). Most commonly, the demand systems used in estimation and simulation are aggregate in nature, the aggregate logit system (Werden et al., 1996) and the AIDS system (Hausman et al., 1994) being examples. We conduct our merger simulation using a linearized version of our disaggregate logit demand system. For a discussion of the effect of functional form on merger simulation, see (Crooke et al., 1999). For a non-simulation evaluation of a consummated hospital merger, see (Sacher and Vita, 2001).

In 1997, Tenet Healthcare Corp and Ornda Healthcorp, two FP hospital corporations, merged. Both were national hospital corporations, and both had a substantial presence in California. Of our 374 analysis hospitals in 1995, Ornda owns 21 and Tenet owns 14.

There is overlap in the service areas of the Tenet and Ornda hospitals. Tenet operates nine and Ornda seven hospitals in Los Angeles County; each operates one in San Diego county; and Ornda operates two and Tenet operates one in San Luis Obispo County. There are, however, 101 and 23 hospitals respectively in Los Angeles and San Diego Counties; whereas there are only five in San Luis Obispo County, of which Tenet and Ornda own the three largest. The FTC permitted the merger to go through, but required in a consent order that the merged entity divest one hospital, French Hospital Medical Center, in San Luis Obispo. This hospital was subsequently divested to Vista Hospital Systems, which also 
Table 8: San Luis Obispo County Hospitals

\begin{tabular}{llrrrr} 
Hospital & Owner & P & D & Beds & Distance \\
\hline \hline French & Ornda & 4434 & 2179 & 147 & 0.28 \\
General & County & 4577 & 255 & 46 & 0.72 \\
Sierra Vista & Tenet & 4134 & 3722 & 186 & 0.99 \\
Arroyo Grande & Vista & 3477 & 546 & 65 & 12.03 \\
Twin Cities & Tenet & 4216 & 1683 & 84 & 19.21 \\
\hline Marian Med Ctr & Catholic & 3289 & 2240 & 225 & 26.24 \\
Valley Cmty & Ornda & 4439 & 2313 & 53 & 26.79
\end{tabular}

owns Arroyo Grande Hospital in the county.

In our merger simulation, we analyze the Tenet/Ornda merger under three different scenarios. First, we simulate the merger assuming no divestiture of French Hospital. Second, we simulate the merger assuming divestiture of French Hospital. Third, we simulate the merger without divestiture under the counterfactual assumption that Tenet and Ornda are NFP. The idea of the third simulation is to test the theory that NFP hospitals behave differently after gaining market power through a merger. In all three mergers, we track the prices in San Luis Obispo, Los Angeles, and San Diego Counties.

It will turn out that San Luis Obispo County is the most interesting, so we provide a description of the hospitals there. There are five hospitals in San Luis Obispo County and two more within fifty miles of San Luis Obispo. The hospitals are described in Table 8.

The first three hospitals are "in town" in San Luis Obispo; the next two are in San Luis Obispo County, and the remaining two are outside San Luis Obispo County but within fifty miles. The distance measure is the distance between the hospitals and the unweighted centroid of the first three hospitals in the table. 


\subsection{Methodology}

Because calculating demand and the derivative of demand is quite computationally burdensome, we approximate the merger effects by linearizing the demand system at the pre-merger prices. Specifically, denote by $P$ and $D$ the $J$-vectors of prices and quantities actually observed in our data. Using the estimated model of demand, we calculate $\frac{\partial D}{\partial P}$, the matrix of demand derivatives at these prices and quantities. Then, it is straightforward to calculate "behavioral" marginal costs pre-merger as:

$$
\left[\frac{\partial C^{B}}{\partial D}\right]=P+\left\{\Theta \circledast\left[\frac{\partial D}{\partial p}\right]\right\}^{-1} D
$$

Since we have allowed scale economies and since the difference in FP and NFP behavior come through their different scale economies, we allow marginal costs to change as a result of the merger. Using estimates from Table 6:

$$
\left[\frac{\partial C^{B}}{\partial D}\right]=\left.\left[\frac{\partial C^{B}}{\partial D}\right]\right|_{D=0}+\Delta * D
$$

where

$$
\Delta=0.12 * I-0.29 * \operatorname{diag}(F P)-0.14 * \operatorname{diag}(N F P)
$$


In the above, FP is a $J$-vector of dummy variables with entries of 1 for for-profit and entries of 0 for government and not-for-profit hospitals. Similarly for NFP. The intercept of the linearized demand is:

$$
\left.D\right|_{P=0}=D-\frac{\partial D}{\partial P} * P
$$

To simulate the merger, we modify $\Theta$ appropriately to reflect the new joint ownership and calculate $\hat{P}$ :

$$
\begin{aligned}
& \hat{P}=\left[\frac{\partial C^{B}}{\partial D}\right]-\left\{\Theta \circledast\left[\frac{\partial D}{\partial p}\right]\right\}^{-1} D \\
& \hat{P}=\left[\left.\frac{\partial C^{B}}{\partial D}\right|_{D=0}+\Delta D\right]-\left\{\Theta \circledast\left[\frac{\partial D}{\partial p}\right]\right\}^{-1} D \\
& \hat{P}=\left.\frac{\partial C^{B}}{\partial D}\right|_{D=0}+\left(\Delta-\left\{\Theta \circledast\left[\frac{\partial D}{\partial p}\right]\right\}^{-1}\right)\left(\left.D\right|_{P=0}+\left[\frac{\partial D}{\partial p}\right] \hat{P}\right) \\
& \hat{P}=\left(I-\left(\Delta-\left\{\Theta \circledast\left[\frac{\partial D}{\partial p}\right]\right\}^{-1}\right) \frac{\partial D}{\partial p}\right)^{-1}\left(\left.\frac{\partial C^{B}}{\partial D}\right|_{D=0}+\left.\left(\Delta-\left\{\Theta \circledast\left[\frac{\partial D}{\partial p}\right]\right\}^{-1}\right) D\right|_{P=0}\right)
\end{aligned}
$$

The merger is simulated by changing the values of $\Theta$, and the changes in ownership are simulated by changing the values of the FP and NFP vectors. 
Table 9: Merger simulation: San Luis Obispo

\begin{tabular}{rrrrrr} 
& & & \multicolumn{3}{c}{ Post-Merger $P$} \\
\cline { 4 - 5 } & & & \multicolumn{2}{c}{ Divestiture } & \\
\cline { 4 - 5 } Hospital & Owner & $P$ & No & Yes & NFP \\
\hline \hline French & Ornda & 4434 & 6987 & 4471 & 6837 \\
General & County & 4577 & 5546 & 4608 & 5513 \\
Sierra Vista & Tenet & 4134 & 6175 & 4205 & 6129 \\
Arroyo Grande & Vista & 3477 & 4214 & 3640 & 4188 \\
Twin Cities & Tenet & 4216 & 6291 & 4262 & 6279 \\
\hline Marian Med Ctr & Cath & 3289 & 3613 & 3319 & 3607 \\
Valley Cmty & Ornda & 4439 & 4911 & 4514 & 4917
\end{tabular}

Table 10: Merger simulation: by location

\begin{tabular}{|c|c|c|c|c|c|}
\hline \multirow[b]{3}{*}{ Area } & \multirow[b]{3}{*}{ Owner } & & \multicolumn{3}{|c|}{ Post-Merger $P$} \\
\hline & & & \multicolumn{2}{|c|}{ Divestiture } & \multirow[b]{2}{*}{ NFP } \\
\hline & & $P$ & No & Yes & \\
\hline \multirow[t]{2}{*}{$\overline{\text { San Luis Obispo }}$} & Tenet/Ornda & $\overline{4238}$ & $\overline{6434}$ & $\overline{4294}$ & $\overline{66366}$ \\
\hline & all & 4199 & 6263 & 4261 & 6198 \\
\hline \multirow[t]{2}{*}{ Los Angeles } & Tenet/Ornda & 4671 & 4702 & 4702 & 4691 \\
\hline & all & 4274 & 4278 & 4278 & 4277 \\
\hline \multirow[t]{2}{*}{ San Diego } & Tenet/Ornda & 3596 & 3613 & 3613 & 3610 \\
\hline & all & 3932 & 3934 & 3934 & 3934 \\
\hline \multirow[t]{2}{*}{ Remainder } & Tenet/Ornda & 4699 & 4740 & 4714 & 4739 \\
\hline & all & 4650 & 4655 & 4651 & 4655 \\
\hline
\end{tabular}

\subsection{Results}

In Table 9, we present the effects of the merger on the hospitals in and around San Luis Obispo County. The columns, beginning with the third, are the price in the data, the price after the Tenet/Ornda merger with no divestiture, the price after the Tenet/Ornda merger with divestiture of French Hospital to Vista, and the price after the Tenet/Ornda merger assuming no divestiture and that Tenet and Ornda are NFP. ${ }^{27}$

\footnotetext{
${ }^{27}$ Notice, when we change the ownership of these hospitals to NFP, we do not change their marginal costs, only their scale economies. The objective of the exercise is to test whether otherwise observationally equivalent hospital mergers are different if the ownership of the hospitals is FP or NFP
} 
The findings summarized in this table are that the Tenet/Ornda merger without the divestiture leads to a large price increase at the Tenet and Ornda hospitals in the county: $58 \%$ at French and $49 \%$ at Sierra Vista and Twin Cities. The competing hospitals also saw substantial price increases, $21 \%$ at General and at Arroyo Grande.

By contrast, with the divestiture of French Hospital, the price increases were very small at less than two percent for each of the hospitals. Moreover, changing the ownership of the chains to NFP has virtually no effect on the post-merger price increase, as the NFP Tenet/Ornda firm raises its prices by roughly the same amount as the FP Tenet/Ornda.

In Table 10, we look at the price effects statewide. Here, we report the same columns. The entries in the table, however, are quantity-weighted prices at the hospitals in each geographic unit. For example, $\$ 6,434$ is the quantity-weighted average price for Tenet/Ornda hospitals post-merger in San Luis Obispo county for the no-divestiture merger, and $\$ 6,263$ is the postmerger quantity-weighted average price at non-Tenet/Ornda hospitals in San Luis Obispo County for the no-divestiture merger.

These results confirm the previous analysis that there would have been a strong effect in San Luis Obispo County of this merger absent the divestiture. In addition, the table shows that the merger has little effect on statewide prices or on prices in either Los Angeles or San Diego Counties. The small effect for the remainder of the state comes principally from Valley Community (see Table 8), which is near but not in San Luis Obispo County. 


\section{Conclusion}

In this paper we have estimated a structural model of hospital competition and used the estimates to simulate the effect of a merger. We take advantage of detailed micro data on individuals and firms to estimate demand and supply. We find that hospitals face significant, but not large, elasticities of demand for their services. NFP hospitals set lower prices, but have higher markups than do FPs, due to lower (behavioral) marginal costs. Our merger simulation reveals no difference between NFPs and FPs in their willingness to exploit merger created market power. In particular, the merger we simulate was one in which the FTC intervened and forced divestiture of one of the hospitals belonging to the merging firms. Our simulations show post-merger price increases of up to $58 \%$ absent the FTC's intervention.

This paper provides more evidence on the nature of competition in differentiated product oligopoly industries, and a particularly important industry at that. Spatial differentiation is important in this industry and bestows firms with market power. Market power is a real issue in this industry, due to the small number of hospitals in many markets.

These results have important implications for policy. Thus far, the U.S. antitrust enforcement agencies have not treated NFP hospital mergers differently. NFPs have defended themselves by claiming that, since their objective is to benefit the community, they would not exploit any market power gained as a result of merger. The courts have been sympathetic to this view and rejected government requests to block mergers between NFP hospitals. Our results indicate that, at least on average for the hospitals in our data, this is not correct. 


\section{References}

(1997). Hospital statistics, emerging trends in hospitals, 1996-7 edition. American Hospital Association, Chicago, IL.

Anderson, S., dePalma, A., and Thisse, J. (1992). Discrete choice theory of product differentiation. MIT Press.

Baker, J. and Breshahan, T. (1985). The gains from merger or collusion in product-differentiated industries. Journal of Industrial Organization, 33:427-44.

Berry, S. (1994). Estimating discrete-choice models of product differentiation. RAND Journal of Economics, 25(2):242-62.

Berry, S., Levinsohn, J., and Pakes, A. (1995). Automobile prices in market equilibrium. Econometrica, 60(4):889-917.

Berry, S., Levinsohn, J., and Pakes, A. (1998). Differentiated products demand systems from a combination of micro and macro data: the new car market.

Capps, C., Dranove, D., Greenstein, S., and Satterthwaite, M. (2001a). The silent majority fallacy of the elzinga-hogarty criteria: a critique and new approach to analyzing hospital mergers. working paper, http://www.kellogg.nwu.edu/Faculty/satterthwaite/Research/researchpage.html.

Capps, C., Dranove, D., and Satterthwaite, M. (2001b). Competition and market power in option demand markets. working paper, http://www.kellogg.nwu.edu/Faculty/satterthwaite/Research/researchpage.html.

Crooke, P., Froeb, L., Tschantz, S., and GJ, W. (1999). The effects of assumed demand form on simulated postmerger equilibria. Review of Industrial Organization, 15:205-17.

Davis, P. (2000). Spatial competition in retail markets: movie theaters. unpublished manuscript, MIT.

Dranove, D. and Ludwick, R. (1999). Competition and pricing by nonprofit hospitals: a reassesment of lynk's analysis. Journal of Health Economics, 18:87-98.

Dranove, D. and Satterthwaite, M. (2000). The industrial organization of health care markets. In Culyer, A. and Newhouse, J., editors, Handbook of health economics, pages 1093-1139. Elsevier Science, North-Holland, New York and Oxford.

Dranove, D. and White, W. (1994). Recent theory and evidence on competition in hospital markets. Journal of Economics and Management Strategy, 3(1):169-209.

Dubin, J. and McFadden, D. (1984). An econometric analysis of residential eclectric appliance holdings and consumption. Econometrica, 52(2):345-62. 
Gaynor, M. and Haas-Wilson, D. (1999). Change, consolidation, and competition in health care markets. Journal of Economic Perspectives, 13(1):141-64.

Gaynor, M. and Vogt, W. (2000). Antitrust and competition in health care markets. In Culyer, A. and Newhouse, J., editors, Handbook of health economics, chapter 27, pages 1405-87. Elsevier Science, North-Holland, New York and Oxford.

Hausman, J. and Leonard, G. (1997). Product differentiation: economic analysis of differentiated products mergers using real world data. George Mason Law Review, 5.

Hausman, J., Leonard, G., and Zona, J. (1994). Competitive analysis with differentiated products. Annales d'Economie et Statistique, 34(2):159-80.

Jaklevic, M. (2002). Tired trend. Modern Healthcare, 32(26):10.

Keeler, E., Buchanan, J., Rolph, J., Hanley, J., and Reboussin, D. (1988). Episodes of medical treatment in the health insurance experiment. RAND publication R-3454-HHS.

Keeler, E., Melnick, G., and Zwanziger, J. (1999). The changing effects of competition on non-profit and for-profit hospital pricing behavior. Journal of Health Economics, 18:69-86.

Lakdawalla, D. and Philipson, T. (1998). Nonprofit production and competition. NBER Working Paper \#6377.

Lee, M. (1971). A conspicuous production theory of hospital production. Southern Economic Journal, 38(1):48-58.

Lesser, C. and Ginsburg, P. (2001). Back to the future? New cost and access challenges emerge: initial findings from HSC's recent site visits, Issue brief \#35. Center for Studying Health Systems Change.

Lynk, W. (1995). Nonprofit hospital mergers and the exercise of market power. Journal of Law and Economics, 38:437-61.

Lynk, W. and Neumann, L. (1999). Price and profit. Journal of Health Economics, 18:99-105.

Manning, W., Newhouse, J., Duan, N., Keeler, E., Leibowitz, A., and Marquis, M. (1987). Health insurance and the demand for medical care: evidence from a randomized experiment. American Economic Review, 77(3):251-77.

Manuszak, M. (1999). Firm conduct in the hawaiian petroleum industry. unpublished manuscript, Carnegie Mellon University.

Muris, T. (1997). Product differentiation: economics and antitrust. George Mason Law Review, 5:303.

Nevo, A. (2000). Mergers with differentiated products: the case of the ready-to-eat cereal industry , 31, 395?421. RAND Journal of Economics, 31(3):395-421. 
Newhouse, J. (1970). Toward a theory of nonprofit institutions: an economic model of a hospital. American Economic Review, 60(1):64-74.

Newhouse, J. (1993). Free for all? lessons from the rand health insurance experiment. Harvard University Press.

Pauly, M. and Redisch, M. (1973). The not-for-profit hospital as a physicians' cooperative. American Economic Review, 63(1):87-99.

Pinkse, J., Slade, M., and Brett, C. (2002). Spatial price competition: a semiparametric approach. Econometrica, 70(3):1111-53.

Sacher, S. and Vita, M. (2001). The competitive effects of a not-for-profit hospital merger: a case study. Journal of Industrial Economics, 49(1):63-84.

Seim, K. (2001). Spatial differentiation and firm entry: the video retail industry. unpublished manuscript, Yale University.

Simpson, J. and Shin, R. (1997). Do non-profit hospitals exercise market power? unpublished manuscript, Federal Trade Commission.

Thomadsen, R. (2002). Price competition in industries with geographic differentiation: measuring the effect of location on price in the fast food industry. unpublished manuscript, Columbia University.

Town, R. and Vistnes, G. (2001). Hospital competition in hmo networks. Journal of Health Economics, 20(5):733-53.

Werden, G. (1997). Simulating unilateral competitive effects from differentiated products mergers. Antitrust, 11(2).

Werden, G. and Froeb, L. (2000). An introduction to the symposium on the use of simulation in applied industrial organization. International Journal of the Economics of Business, 7(2):133-7.

Werden, G., Froeb, L., and Tardiff, T. (1996). The use of the logit model in applied industrial organization. International Journal of the Economics of Business, 3(1):83-105. 


\section{A Appendix}

\section{A.1 Proof of Assertion from Page 9}

\section{Assertion:}

The problem:

$$
\begin{aligned}
\min _{\chi(\bullet), q(\bullet)} \int_{R_{i}} \sum_{j} \chi_{j}\left(R_{i}\right) p_{j} q\left(R_{i}\right) d F_{R_{i}} \\
\text { s.t. } \quad \int \sum_{j} v\left(q_{i}, R_{i}, S_{j}\right) d F_{R_{i}} \geq \bar{v}
\end{aligned}
$$

is equivalent to solving

$$
\min _{\chi, q} \sum_{j} p_{j} q-\lambda v\left(q, R_{i}, S_{j}\right)
$$

for each consumer individually, where $\lambda$ is chosen such that the constraint is satisfied at the solution.

\section{Proof:}

Consider a set of $\chi^{*}\left(R_{i}\right)$ and a $q^{*}\left(R_{i}\right)$ satisfying the above problem for each $R_{i}$ for a $\lambda$ which causes the constraint to be satisfied. Now consider any $\chi\left(R_{i}\right)$ and $q\left(R_{i}\right)$ satisfying the constraint. By the optimality: 


$$
\sum_{j} \chi_{j}^{*}\left(p_{j} q_{i}^{*}-\lambda v\left(q_{i}^{*}, R_{i}, S_{j}\right)\right) \leq \sum_{j} \chi_{j}\left(p_{j} q_{i}-\lambda v\left(q_{i}, R_{i}, S_{j}\right)\right)
$$

Now, integrating both sides over $R_{i}$ and imposing the constraint:

$$
\begin{aligned}
\int_{R_{i}} \sum_{j} \chi_{j}^{*}\left(p_{j} q_{i}^{*}\right)-\lambda \bar{v} & \leq \int_{R_{i}} \sum_{j} \chi_{j}\left(p_{j} q_{i}\right)-\lambda \bar{v} \\
\int_{R_{i}} \sum_{j} \chi_{j}^{*}\left(p_{j} q_{i}^{*}\right) & \leq \int_{R_{i}} \sum_{j} \chi_{j}\left(p_{j} q_{i}\right)
\end{aligned}
$$

This proves the result. 


\section{A.2 First-Stage Regression Estimates}

First-stage regression for average utility 2SLS $($ dependent variable $=$ price in $\$ 1000 \mathrm{~s}$ )

\begin{tabular}{r|l} 
Variable & Estimate \\
\hline constant & 2.38 \\
& $(0.64)$ \\
$\frac{D_{j} I V}{\partial D_{j}} \partial$ & 0.12 \\
$\partial p_{j}$ & $(0.04)$ \\
$W$ & 2.20 \\
& $(0.63)$ \\
$D^{I V}$ & $-4.89 \times 10^{-5}$ \\
& $\left(7.87 \times 10^{-5}\right)$ \\
FP & 0.20 \\
& $(0.26)$ \\
NFP & -0.29 \\
& $(0.23)$ \\
Teach & 0.74 \\
& $(0.26)$ \\
tech & $-1.22 \times 10^{-3}$ \\
& $\left(1.78 \times 10^{-2}\right)$ \\
\hline$R^{2}$ & 0.086 \\
$F$ & 4.91 \\
$N$ & 374 \\
\hline &
\end{tabular}

